\title{
El persistente impulso a resemantizar
}

\author{
Victorino Zecchetto
}

\section{Introducción: semantizar y resemantizar}

Los lenguajes humanos fueron inventados para 'semantizar la realidad', esto es, para expresar los contenidos y sentidos del mundo por medio de alguna

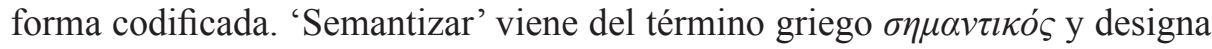
la significación de las palabras. De modo más amplio, la semántica (parte de la semiótica) estudia y analiza los procesos de significación de los signos, textos y discursos que circulan diacrónica y sincrónicamente por la sociedad. El uso de la palabra 'resemantizar' está relacionado con la anterior, pero indica un proceso inverso, porque busca dar realce a un sentido ya existente, o a uno nuevo recuperado, ya sea en forma total o parcial. Como en otros numerosos términos, el prefijo 're' tiene el sentido de volver a poner algo, de añadir algo a una cosa anterior, o bien, alude a un efecto que trasciende una obra original. Pensemos en palabras como 're-fundar', 're-presentar', 're-producir', 're-percutir', 'reposicionar', re-organizar', 're-equilibrar, re-pintar', entre otras. Todas estas palabras indican una variedad de acciones cuyo elemento común consiste en indicar la acción de añadir, desarrollar, construir, a partir de un fundamento existente. La tarea de resemantizar arranca, entonces, de un sentido dado de antemano, y su objeto es expresar una nueva configuración. Se trata de una acción que puede tener pretensiones diversas. A veces se instala por la pérdida de contenidos semánticos de un determinado lenguaje; otras, tiene el fin de recuperar una degradación simbólica o mítica, o es un intento de innovación creativa.

En conclusión, resemantizar es un vocablo que se refiere a la operación semiótica de transformar el sentido de una realidad conocida o aceptada para renovarla o para hacer una transposición de modelo, creando una entidad distinta, pero con alguna conexión referencial con aquélla, de modo que esta última asume un nuevo significado que la primera no tenía. Vemos que la resemantización mezcla o integra aspectos de la analogía, de la metáfora y de la polise-

Profesor de Semiótica y autor de varios libros sobre Comunicación y actitud crítica,Eexdirectivo de SIGNIS.vzecchetto@donboscoalmagro.org.ar 
mia, ensamblándolos con el propósito de hacer algo novedoso. De la analogía se apodera del analogatum princeps; es decir, de la obra inspiradora y que contiene una cosmovisión o perspectiva que da lugar a una experiencia básica del mundo. El analogado principal es la raíz o punto de partida asumido intelectualmente. La metáfora, en cambio, en la resemantización se usa como un instrumento metodológico para la creación de la nueva obra. ¿Cómo acontece este fenómeno de resemantización?

\section{El doble movimiento del proceso}

Para entender el proceso de resemantización interesa señalar los dos procedimientos que integran esa actividad de transformación: el primero es el registro de lo asentado; y el segundo, el trabajo mismo de construcción de la obra. Esos dos movimientos marcan el trabajo final.

\section{a. Primer movimiento: registrar lo asentado}

Es preciso observar, ante todo, la naturaleza social de los procesos semióticos. Los significantes y las significaciones de los signos, símbolos, textos y discursos, advienen al interior de los grupos sociales y culturales. Hay creaciones que quedan fijadas en el tiempo y, en cierto modo, se tornan 'clásicos' referenciales para todo un grupo o una sociedad.

En occidente son conocidos muchos mitos, eventos y personajes históricos que se han cristalizado con un significado paradigmático. En siglos pasados se consignaron simbólicamente relatos bíblicos, tragedias griegas, obras de narradores medievales, historias llegadas del oriente, y muchos eventos históricos que pasaron a acompañar los imaginarios sociales y colectivos.

En Latinoamérica circulan y se conocen mitos de los pueblos indígenas primitivos. Otros se crearon después, como las historias patrias de cada pueblo, que forjaron sus relatos para expresar aquellos valores considerados un patrimonio que hay que conservar. La revolución francesa impuso su incisiva trilogía: "Libertad, Igualdad y Fraternidad", en otras naciones de nuestro continente se forjó el eslogan "Revolución o muerte". 
También ciertas manifestaciones de la naturaleza, e incluso algunos monumentos arquitectónicos destacan por ser portadores de un fuerte contenido cultural simbólico: las Cataratas de Iguazú, las pirámides de Egipto o las de México, los 'moais' (estatuas de piedra) de la Isla de Pascua, la Gran Muralla China, son solo algunos ejemplos de los numerosísimos que existen.

En síntesis, el proceso de ampliación semántica suele partir de elementos registrados y asumidos socialmente, los que luego son configurados desde algunas clases y estilos de lenguajes que permiten descifrarlos con otras significaciones.

A esos fenómenos de resemantización se les atribuye una triple función:

- Ser modelos simbólicos que fungen de contexto-espectáculo donde un pueblo ve reflejados aspectos de su entorno y de su vida.

- Influenciar las relaciones de un grupo social, dándole un paradigma que produce 'efectos de sentidos' u otras repercusiones psicosociales.

- Ser portadores de imaginarios en vista al consumo. Los medios de comunicación social hoy forman parte de esas estrategias comerciales en un contexto de vida globalizada.

\section{b. Segundo movimiento: elaborar la versión resemantizada}

Hemos dicho que en el montaje de la resemantización se produce una transposición de modelos con el objetivo de reconstruir otro. Esta operación se basa en el supuesto de que los ciudadanos (o un grupo social significativo) que se desenvuelven en su contexto de vida cotidiana, conocen o tienen acceso a determinadas formas o expresiones culturales consignadas en el seno de la sociedad, y que para ellos poseen un significado corroborado por la práctica.

Ya que la resemantización forma parte del continuo proceso de simbolización a la que está sometida nuestra sociedad, pasa a ser un elemento característico de la vida cultural. En efecto, los cambios constantes de sentidos y de significados de los objetos, de los eventos, de los personajes, se producen en las expresiones mediáticas, y acaban reemplazando los anteriores sentidos originales y conocidos. 
Los creadores que resementatizan una obra (literaria, de arte, arquitectónica, musical, audiovisual, etcétera), o un evento (político, religioso, cultural, social...), piden permiso (a veces) para adueñarse de ella, avanzan y se la devuelven a la sociedad con otra mirada. Les indican a los ciudadanos que debemos acceder al mundo de ideas, deseos o sentimientos, prestando atención ahora a las intencionalidades encerradas en las nuevas creaciones que miden sus fuerzas con los viejos significados.

Todo va cambiando y se resemantizan palabras, frases, modas, discursos, figuras, imágenes, mitos, creencias, destinos... No es exagerado decir que la resemantización es la expresión de un "mundo en fuga".

\section{Formas de resemantización}

Los rumbos de la resemantización son múltiples y toman cuerpo en los géneros y las formas de cada creación. Una vez que un autor decide trascender el 'analogado principal' para resementizarlo trata de hallar la figura o el género capaz de exhibir la nueva creatura.

Prestemos atención a algunas muestras de resemantización realizadas con matices, tonos y lineamientos dispares unos de otros, pero que manifiestan las riquezas y/o limitaciones de tales procedimientos.

\section{a. En el arte}

En las artes (literatura, pintura, música, teatro, cine, fotografía...), la resemantización se hace presente cada vez que un artista se sitúa en la inminencia de otra obra ya realizada, y propone nuevos significados e interpretaciones formales o de contenido. Su intento es hacer posible otro punto de vista, probando así que lo real puede decirse todavía de otra manera.

Vamos a explorar algunos ejemplos.

\section{- Literatura y mitos}

La literatura universal posee ricas y atractivas narraciones míticas. Ellas plantean interrogantes acerca del sentido de muchos acontecimientos y accio- 
nes humanas, como formas para entender el destino de la vida. La resemantización de mitos es un camino transitado por muchas obras literarias que han visto en ellos un fecundo potencial de universalidad. Citamos, a modo de ejemplos, solo dos casos que han inspirado la literatura teatral.

Antígona: tragedia de Sófocles, basada en el mito de Antígona fue representada por primera vez en 442 a.C. En Antígona se enfrentan dos concepciones de deber: 'el deber familiar', caracterizado por el respeto a las normas religiosas, esto lo representa la figura de Antígona, una mujer que desea darle honras fúnebres al cuerpo de su hermano Polícines; otro principio es el del 'deber civil', caracterizado por el cumplimiento de las leyes del Estado y encarnado en Creonte (que prohibió enterrar el cuerpo de Polícines muerto como traidor a la patria). Además la obra establece una oposición entre el modo en que las dos hermanas, Antígona e Ismene, encaran el problema y se enfrentan al cumplimiento de uno u otro deber.

Resemantización: Antígona Vélez (1951) obra teatral de Leopoldo Marechal, escritor argentino (...).

La acción de Antígona Vélez se desarrolla en una estancia llamada "La postrera", en los confines de la pampa y el desierto argentinos, en el siglo XIX, época de la llamada "Conquista del Desierto", ámbito y contexto donde se desarrolla la tragedia.

La obra comienza en el momento que los dos hijos de don Luis Vélez (Ignacio y Martín) se pelean en una guerra y se matan entre sí. Martín Vélez murió defendiendo "La postrera", pero Ignacio que se pasó al bando de los pampas, de los indios, ha muerto atacándola. Facundo Galván prohíbe darle un entierro honroso a Ignacio. Pero Antígona enfrenta a Galván y con el apoyo de su prometido Lisandro Galván, cumple su deseo. Esto les costará a ambos la vida; Marechal en su pieza teatral resemantiza la tragedia de Sófocles, y la coloca en otro contexto histórico, muy nuestro como es la vida en la pampa argentina recordando la obra de Martín Fierro y su exaltación trágica.

El infierno. Es una creencia religiosa que se ha vuelto 'mitológica' en el revestimiento del lenguaje humano. En el cristianismo ha sido inmortalizada de muchas formas, la más conocida tal vez es la Divina comedia de Dante 
Alighieri (1265-1321). Éste influenció numerosos otros relatos sobre el infierno, como también pinturas y obras de arte hechas durante siglos en occidente. El concepto de 'infierno' sostiene que la gente malvada que no se arrepiente de sus grandes pecados, recibirá como retribución más allá de la muerte, graves penas infernales. La principal será la privación de la gozosa presencia de Dios y, en consecuencia, estar apartados de la infinita dicha del paraíso. La tradición popular cristiana alimentó la imaginería del infierno, creando tormentos físicos fantasiosos, con llamas inextinguibles, ambientes de castigos angustiantes, con diablos capaces de inventar continuamente efectos especiales para torturar a los condenados.

Resemantización. A puertas cerradas (À huis clos), pieza teatral del filósofo Jean Paul Sartre, escrita en 1944, da una descripción existencial del infierno y resemantiza psicológicamente sus tormentos. En la obra actúan solo cuatro personajes, uno de ellos el Mayordomo es símbolo del demonio. Los otros tres son condenados por sus fechorías y deben expiar sus culpas compartiendo un mismo cuarto, sin espejos, ni ventanas y una sola puerta que luego se cerrará con llave. Solo hay tres sillones y nadie jamás podrá dormir. El infierno consiste en estar allí, en ese lugar sin tiempo, donde todo es presencia del otro, con la obligación de escuchar sus pensamientos y la imposibilidad de encerrarse en sí mismo, de aislarse; la tortura es no poder deshacerse de los demás, esa condenación se expresa sobre todo, en sentirse absorbido por la mirada de los otros personajes. En esta obra teatral está la frase célebre: "L'enfer c'est les autres" ("El infierno son los otros"). Sartre, se aparta del concepto tradicional del infierno, resemantiza ese mito y representa la desdichada eternidad, como el horror de no poder ocultar el propio vacío existencial, porque se vive expuesto a la mirada del otro, que ahora se ha vuelto tormento y castigo.

\section{- La pintura}

Las obras pictóricas despliegan y comunican un sentido. La estrategia de resemantizantización -desde esas fuentes- ensaya otros efectos retóricos para abrir caminos a nuevas interpretaciones. La pintura conoce una fecunda trayectoria de este método de creaciones. Citamos algunos ejemplos: 
-Uno de los intentos más originales de resemantización de la naturaleza vegetal lo ha propuesto el pintor renacentista Giuseppe Archiboldi (1527-1593). Son famosos sus retratos bizarros y extravagantes, combinando figuras de frutas, verduras, hojas y otros vegetales, para representar personajes alegóricos como las estaciones del año. Otras veces pinta instrumentos agrícolas o libros para crear sus personajes. Sus obras están hechas con una elevada técnica, y trasmiten un fino sentido irónico.

-En nuestro tiempo cabe mencionar al artista plástico argentino Daniel Santoro (nacido en Buenos Aires en 1954). Su iconografía retrata el imaginario peronista, sus iconos, sus mitos, su teatralización de la política. El artista rastrea los fervores intrigantes de los relatos oficiales de realismo mágico peronista, en el que abunda la estética de ritos y de léxicos recargados de signos y de simbolismos. Para nuestro caso es de interés su obra El símbolo, una creación que ironiza el ideal peronista de estar junto a la clase popular a costa de la educación. Santoro lo hace resemantizando forma y contenido: la forma derivada del famoso cuadro de René Magritte, pintor belga (1898-1967) La traición de las imágenes, con la que aprovecha para emplazar el problema de la representación y la esencia del arte. La obra imita el título y lo resemantiza: "Esta no es una alpargata"; así vuelca el mensaje de clara alusión a la matriz peronista, y lo revierte para simbolizar la tensión argentina entre civilización y barbarie.

-Un tercer ejemplo nos lleva a recordar el trabajo de resemantización hecho por el artista Francis Bacon (1909-1882) sobre el retrato del Papa Inocencio X pintado por el español Diego Velázquez (1599-1660) en Roma en 1650. La faceta de retratista sensible hizo que Velázquez mostrara la figura controvertida de este Papa como un hombre de compostura solemne y de esquiva frialdad. Sin embargo Velázquez, conocido como un hombre de pocas palabras y reservado, nunca comentó su obra.

Diversa es la versión que presenta Bacon (realizada en 1953). Interpreta a un personaje con rasgos espectrales. Su retrato muestra a Inocencio X deformado, con rostro crispado y con un grito angustioso. Tiene los puños cerrados signo de rebelión al destino que le arrebata el poder que ya llega a su fin. La historia cuenta que este Papa era desconfiado, nepotista e intrigante, para nada popular. Murió sin que nadie lo llorara. La tela de Bacon expresa a un hombre de poder, cuyo cuerpo se deshace y se desmorona por todos lados. Acá aparece 
el trabajo detallado de una fina resemantización de una obra clásica puesta en un nuevo contexto con una significación de infamia y desagrado.

$\mathrm{El}$ arte se esfuerza por mantenerse en conexión con los movimientos sociales de su época, con las utopías, las aspiraciones psicológicas o incluso con las frustraciones que causa la realidad cotidiana. La estética elije aquello que puede resultar una alternativa simbólica a un presente duro o nebuloso.

\section{- El cine}

Además de la pintura y el arte plástico, el buen cine es, sin duda, uno de los espacios artísticos donde más se reelaboran las experiencias, los vaivenes de las formas de vivir y las filosofías que las inspiran.

La historia del cine conoce la práctica constante de directores que emprenden redefiniciones temáticas y estéticas de obras conocidas, y las trabajan con creatividad y estilo propio. Algunos son capaces de retomar personajes, tiempos, zonas, paisajes y lenguajes, y darles una nueva identidad. Parece ser que el destino del cine, cada vez más, consiste en decir lo que otros han dicho, pero alimentando ese lenguaje audiovisual, con la visión del presente, y abrirse a la vida diversificada para entretener a la gente de hoy, o para mostrar una visión de la realidad desde el abismo del ahora que interroga. Sin embargo, si hablamos del 'cine comercial' no creo exagerado afirmar que tiene una autonomía limitada, y que el secreto de contar historias, hoy consiste en realizar intersecciones complejas entre creatividad, finanzas e industria. Existen indudablemente obras valiosas y de calidad. Nadie negará la excelencia de un filme como Titanic y su vigorosa resemantización del conocido naufragio del trasatlántico de 1912. El costo de la película fue elevadísimo, pero las ganancias obtenidas fueran aún mayores.

En los inicios del cine, el pionero George Méliés ya en 1902 realizó su obra Viaje a la luna, película de ciencia ficción que dura unos 15 minutos, basada en el libro de Julio Verne De la tierra a la luna. Es una mezcla de imágenes oníricas, con las aspiraciones y las ilusiones de la ciencia, y que anticipó en cierto modo, las futuras conquistas espaciales. Si encuadramos las dos imágenes siguientes en una comparación visual en perspectiva temporal, es claro que la cinta de Méliés en su época funcionó como un 'architexto' de una obra litera- 
ria, mientras que la foto histórica del descenso en la luna en 1969, resemantiza visualmente (la fuerte evidencia de la bandera que se destaca sobre el fondo negro) el potencial tecnológico norteamericano en un contexto nacionalista, en plena época de guerra fría con la Unión Soviética.

Debido a la infinita filmografía mundial, nos es suficiente señalar algunos casos del cine latinoamericano realizados a partir de 2000, y que resultan emblemáticas obras de resemantización.

- Una cinta destacada es la brasilera de Fernando Meirelles y Kátia Lund: Ciudad de Dios (2002), inspirada en la novela de Paulo Lins (1997). La película narra las guerras y violencias en una favela de Río de Janeiro. A pesar del realismo (escenas violentas y con actores extraídos del lugar mismo de la historia), la forma y la estética adoptadas le dan al filme un sesgo frenético y alucinante, con imágenes emocionantes, escenas cruzadas y veloces que, a lo largo de toda la narración, sostienen la atención del público. Todo pareciera que la violencia es ineluctable, un torbellino del que nadie puede escapar. Y sin embargo, se mantiene la tesis de que no todo se hunde y que es posible eludir ese destino de muerte. La película es una invitación a embocar un camino diverso. Su resemantización es justamente eso, que ese sueño se puede lograr y que la condición del ser humano no es la fatalidad de la violencia.

-Otra película de inestimable valor interpretativo es Diario de motocicletas (Argentina, 2004), del director brasileño Walter Salles. Este simpático filme está inspirado en dos 'diarios' de viaje: uno del Che Guevara y el otro de Alberto Granado. Dos jóvenes argentinos (Guevara y Granado) en 1952, emprendieron un viaje por carretera, para descubrir el mundo y la vida de América Latina. Esos jóvenes universitarios (el Che tenía 23 años y Alberto 29), al final de su viaje y después de haber estado en contacto con gentes y pueblos diversos; de haber escuchado sus problemas y compartido sus sueños; haber pisado tantos lugares originales y escuchado historias de hombres y mujeres de países hermanos, se dieron cuenta de que esa experiencia les había iluminado y transfigurado la vida, dándoles una mirada nueva para juzgar el continente. Leyendo los diarios del Che y de Granado el director de esta película, no modeló un escenario artificial, sino que 'fue viajando' a través de los países de América Latina, como si estuviera acompañando a los dos amigos que iban recorriendo el territorio en motocicleta. No se piense entonces, en retratos de revolucionarios ni en jóvenes viajeros que 
encaran cada nueva etapa o acontecimiento con decisiones de luchas heroicas. Todo se desarrolla en la contemplación de escenarios culturales y humanos, donde no falta el humor, como tampoco las reflexiones críticas que les servirán a los protagonistas para ir construyendo su personalidad y su visión de la historia. La estética, pues, remodeló la figura tradicional que se tiene del 'Che revolucionario'. La banda sonora del filme, ayuda a dar un tratamiento al tema, sacándolo un poco del tiempo, para mostrar la perennidad de tantos ideales juveniles que se gestan a medida que se va viajando. El estilo de la película resemantiza la figura del Che colocándola en un contexto generalmente desconocido.

\section{- La música}

Sobre el relato y el imaginario social ruso, acerca de la patriótica resistencia a la invasión napoleónica ocurrida en 1812, se han creado varias obras artísticas. En el campo musical se destaca la conocida y grandiosa Obertura 1812 del músico Piort Ilich Chaikovski. El título no es gratuito, rememora un hecho histórico importante para el pueblo ruso. La obra fue compuesta en ocasión de los festejos nacionales que en 1882 celebraban esa gesta heroica. La resemantización plasmada por Chaikovski resultó particularmente triunfal, hasta tal punto que en 1891 el ruso dirigió su obra también en Estados Unidos, en la ciudad de Nueva York, que entonces conmemoraba el día de su independencia. En la Obertura 1812 los instrumentos musicales recrean los eventos sucedidos después de la incierta batalla de Borodino, cuando Napoleón avanzó para entrar en Moscú. La música envuelve de significado nacionalista la resistencia que acabó con la victoria sobre Napoleón. Éste, a pesar de haber tomado la capital tuvo que retirarse al contemplar que todo era fuego e incendio. Su retirada fue catastrófica. Chaikovski representa con sonidos esas escenas. La música sagrada inicial evoca el himno nacional ruso; luego suenan reiteradamente los acordes de la Marsellesa francesa. Pero de pronto cambia el ambiente sonoro, se escuchan salvas de cañón y los repiques de campanas de las iglesias de Moscú en alusión al triunfo.

Otro caso análogo de resemantización musical, pero dentro de un contexto histórico preciso y muy particular, lo constituyó el uso pragmático del solemne coral de la Novena sinfonía de Beethoven. Ocurrió en Chile durante la dictadu- 
ra de Pinochet entre 1973 y 1989. Para manifestar disconformidad, resistencia y rechazo a los métodos represores y antidemocráticos de los militares, los grupos y la gente que deseaba la defensa de los Derechos Humanos, cantaban la melodía de la $9^{a}$ Sinfonía: "escucha hermano la canción de la alegría", que se convirtió en símbolo de paz, concordia y justicia en esos lúgubres años.

Si ahora nos volvemos hacia América Latina, nos topamos con un rico repertorio de géneros musicales populares, sometidos a variadas resemantizaciones, donde se reinterpretan milongas, valses, cuecas, zambas, chacareras, chamamés, chamarritas, etcétera. Allí se entretejen estructuras sonoras, y se llevan a cabo reconstrucciones de sentido pertenecientes a manifestaciones músicas regionales, articulando y reinterpretando discursos musicales de lugares diversos, a veces como consecuencia de migraciones, con memorias e identidades culturales múltiples, o incluso con ideologías contrastantes. La canción popular apela a la memoria local y a sus símbolos, al empleo de instrumentos disponibles de calidad dispareja, a estéticas tradicionales mezcladas con expresiones musicales de tecnología más reciente. De ese modo, el lenguaje musical, a menudo, cae en lo inauténtico y deviene funcional al marketing, a las canciones o a los bailes de moda, sin gran calidad artística. Otra música que bien puede ser de mayor calidad, es rechazada porque no se considera apropiada al valor de consumo masivo. Así se van recolocando géneros de una región a otra, con carencia de una estructura musical específica. Se eligen repertorios musicales variados y se tratan temas cambiando su valor semántico, como sucede con cierto tango electrónico, que recae sobre públicos con sentido únicamente de baile. O bien se toca y se interpreta música popular en espacios urbanos con remembranzas y recuerdos de provincias del interior. Hay de todo. Las resemantizaciones musicales, en gran parte, reflejan la misma realidad social que es 'híbrida' como señalan justamente los antropólogos y sociólogos. No interesa ahora emitir juicios de valor sobre el fenómeno, sino destacar que la resemantización musical latinoamericana, envuelve la dinámica misma de producción, difusión y consumo. Los creadores, los intérpretes y los géneros musicales van al encuentro del público y cristalizan su música desde distintas perspectivas, aquellas que la misma historia (y la industria) sugiere y señala, reflejando los significados y los imaginarios del momento. Es ineludible que la música se resemantice de continuo. Después su análisis teórico le pertenece a los especialistas. 


\section{a. En la publicidad comercial}

El rubro publicitario es el que más ejerce el oficio de resemantizar. Siendo que la publicidad comercial trata de imponerse al público consumidor y persuadirlo con el fin de venderle un producto o un servicio, compone modelos y estilos mediáticos en vista a ese objetivo. Los estereotipos que utiliza requieren renovar el 'shock sensorial' permanentemente, para decir lo mismo, cambiando las formas significantes. En efecto, uno de los recursos más frecuentes usado en la publicidad es impactar al público consumidor golpeando la vista y el oído con frases, colores e imágenes, con el propósito de sacudirlo. Observemos, sin embargo, que la creatividad de un comercial solo toca la forma, nunca los contenidos que permanecen idénticos. La excepción la establece la 'publicidad de bien público' que tiene una finalidad distinta de la comercial, ya que apunta a comprometer a los ciudadanos con valores cívicos de solidaridad, busca el cambio de actitudes o de conductas ciudadanas, se preocupa de hacer tomar conciencia de las normas que rigen la vida comunitaria y social.

La tendencia de la técnica publicitaria comercial es resemantizar el mundo y la vida entera, bajo todos sus aspectos. Para ello recurre a hechos históricos o de actualidad, a escritos literarios, a obras artísticas, a monumentos, a paisajes o a fenómenos de la naturaleza, a la experiencia cotidiana o a las extraordinarias. En resumen, todas las cosas pueden cambiar su significado y pasar a integrar el sentido de otra realidad, la que impregna el mensaje publicitario. En los anuncios comerciales, la tarea de resemantización da como resultado variar la percepción de la realidad objetiva, privándola de su sentido original, y someterla a distorsiones o a desintegraciones, usando formas, estilos, tonos adecuados para recubrirla o recrearla.

En las siguientes imágenes ilustramos con algunos ejemplos lo que acabamos de explicar. Es fácil percibir como la estrategia publicitaria asume estilos variados. Puede ser hiperbólica, solemne, desagradable, superficial, equilibrada, chillona, tranquila, odiosa, hilarante... a gusto y placer del consumidor.

En la publicidad hay también resemantizaciones lingüísticas. Muchas frases, eslóganes y dichos, a veces conocidos por pertenecer a personajes famosos, son extrapolados de sus contextos, para indicar otra realidad, otras cosas, 
actitudes, o situaciones, envolviéndolos con nuevos significados. Citamos solo algunos ejemplos:

* (En una publicidad de un equipo de sonido): La vida no se mide por las veces que respiras, sino por aquellos momentos que te dejan sin respiro.

* (Para publicidad de hojas de afeitar): ‘ Varón!' dijo la partera. Este chico se afeará con Legión Extranjera.

* (Publicidad del auto Renault clio): Un joven bien preparado.

* (Publicidad de una cadena de restaurantes): Los perros que nunca duermen.

* (Una consultora de negocios se publicitó con esta frase del antiguo escritor romano Séneca): No hay viento favorable para el que no sabe dónde va.

* (La publicidad de un método para adelgazar, usó esta frase del famoso Cervantes de Saavedra): La verdad adelgaza y no quiebra.

* (Publicidad de un perfume para varón empleó este conocido adagio): El verdadero amigo es aquel que a pesar de saber como eres, te quiere.

\section{b. En la vida política y social}

En general la vida política la hacen personas que, supuestamente, desean cambiar aspectos del destino social presente, y expresan la decisión de romper y remplazar esquemas que consideran superados. Esa tarea exige acabar con un orden y ubicarse en otro. Es frecuente, entonces, hallar en la retórica de los discursos políticos 'resemantizaciones' abundantes y sobre todos los temas. Sus leguajes fácilmente son transgresores respecto a los temas que critican, para afirmar la decisión de sus postulados. Ello conlleva la necesaria resignificación de eventos, de símbolos o mitos, con el objetivo de señalar la dirección redentora de las propuestas destinadas a consagrar la voluntad de construir algo nuevo, un destino diverso. Es conocido el caso de Benito Mussolini que 'resemantizó' el pasado glorioso del imperio romano, e instaló el discurso ideal de una nueva nación poderosa, conquistadora y colonialista en pleno siglo XX. Esa resemantización lo llevó al fracaso.

En Argentina son frecuentes las 'resemantizaciones' que hacen los peronistas del pensamiento de su líder Juan Domingo Perón. Esas interpretacio- 
nes definen 'los dichos' del héroe fundador, atraviesan otros relatos que cada uno compone desde lugares distintos, pero desarrollándolos sobre el derecho histórico de sentirse la expresión de la identidad original. Van sucediéndose, entonces, recreaciones ideológicas, y se forjan idearios, prácticas sociales o acciones políticas diversas, según las resemantizaciones del momento. De un mismo tronco, de la misma raíz 'peronista' nacieron brotes opuestos. Surgió la temible y sangrienta agrupación de ultra derecha 'Triple A' (Alianza Anticomunista Argentina) en la década del setenta. Su jefe era José López Rega secretario y ministro de Perón. Sus miembros cometieron asesinatos de guerrilleros y políticos de izquierda.

Pero del mismo tronco también nació el polo opuesto, los conocidos 'Montoneros' correspondientes a la izquierda peronista y de aspiraciones revolucionarias. Ellos también se calzaron el traje de la violencia y de la sangre, confiados en abrir con las armas el camino de una patria renovada. Más recientes son los nuevos materiales peronistas resemantizados. El relato de Menen neoliberal y globalizado, urdía alabanzas a Perón, mientras el coro sindical peronista reverenció sus discursos y prácticas de capitalismo salvaje. Excavando en las mismas enseñanzas de Perón, la interpretación de los Kirchner se encarriló en otra dirección de ruptura y rebeldía, permitiéndose inventar otro discurso más nacionalista y populista, pero sin tocar el núcleo duro del capitalismo. Así construyó otro ecléctico peronismo, remitiéndose a las figuras sagradas de los primeros ídolos Perón y Evita, para revelar al país 'un modelo' que solamente se trata de llevar adelante profundizándolo.

La historia de los países latinoamericanos muestra muchos ejemplos de 'resemantizaciones políticas'. Cuando se habla de proyectos políticos, siempre hay que rastrear por alguna nebulosa de pensamientos pasados recompuestos, de teorías reestructuradas, de pasiones que llenan los vacíos dejados por otros, de palabras dichas y selladas en otras circunstancias y contextos, pero reasumidas explicando lo que ellas deben significar ahora. Toda resemantización política funda estilos, prácticas y sentimientos. Sus actores han de aprender a decirla con palabras nuevas e inventar identificaciones con un núcleo patriótico anterior renovado y adaptado a la historia presente. Cada discurso político resemantizado tendrá consenso y arraigo profundo, si su elaboración irradia el aroma de lo indecible, si su versión es creíble para las masas, si demuestra ser 
una señal verdadera de que 'lo vuelto a decir' con nuevas expresiones, alza los sentimientos a la esfera de una esperanza creíble.

\section{Conclusión: la vida resemantizada}

Hemos echado una mirada rápida sobre algunas actividades donde se cultiva la resemantización. Tal vez sea justo agregar ahora una reflexión final para contribuir a ensanchar el discurso acerca del fenómeno.

Partamos de una constatación sencilla y simple: la persona humana no es lineal, no trascurre su vida siempre en un sentido homogéneo e igual, sino que varía, innova y multiplica los sentidos de las cosas y de los acontecimientos que vive. Necesita anticiparse a lo que anhela y va a venir, sumergirse en su entorno cotidiano de manera nueva y original, para orientar sus días con miradas proyectivas, modificando incluso el significado de los antiguos mensajes recibidos y experiencias vividas. A esto, en el fondo, se reducen las pugnas generacionales. Ellas representan el modo como cada cual hace su historia, abandonando los lugares de un pasado, con el intento de construir o inventar otro con un sentido modificado. Tal vez nadie logre cambiar radicalmente los valores, pero sí agregarles pedacitos de rebeldías, envolver con otras ideas los códigos que los sustentan. Las pasiones individuales, los conflictos interiores, los desgarramientos sociales, y muchas otras experiencias personales o colectivas, abonan el campo copioso de la resemantización de la historia humana. Los días que pasan son una sucesión de transformaciones, donde a una fase le sucede otra y el mundo mismo es una metamorfosis continua. Pensemos a nivel individual: ¿quién no trata de cambiar ambientes, objetos, contactos, paisajes, experiencias? ¿No es eso un intento de aportarle movilidad a la vida, al comprobar la inexorable caducidad de las cosas y de la historia? Cada generación -y en cierta medida cada persona- busca describir la existencia de otra forma; es decir, resemantizarla para generar experiencias con sensaciones nuevas. De lo simple surge la complejidad de las prácticas y de los lenguajes, así como todo discurso y todo texto mediático dan pie para producir otros.

En su nacimiento todo discurso social, político, religioso, artístico o filosófico es uniforme. Pero con el tiempo, la materia se diversifica, asume los matices que le agregan opiniones innovadoras, toman los rumbos que le va 
asignando la creatividad de los maestros que los vuelven a pensar, desde visiones distintas, lugares, culturas y situaciones de vida diferentes. Se perfilan obras, producciones, corrientes o escuelas. Todas ellas, sin embargo, surgen del primer tronco común que arranca de la humanidad misma, porque apenas despuntó la cultura con el homo sapiens, ésta se expandió por el planeta. Hombres y mujeres ocuparon su tiempo haciendo, rehaciendo, comprendiendo y repensando sus acciones, sus saberes y sus experiencias, que fueron acumulando y almacenando en los galpones de su larga historia.

Observemos, entonces, cómo en las expresiones creativas y en las formas prácticamente ilimitadas del lenguaje, el concepto de contemporáneo no pasa por su pertenencia a nuestra época, sino por el hecho de que una idea, un sentimiento o aspiración no termina de realizarse enteramente y siempre habrá alguien que la haga presente en forma resemantizada.

Cada vez los seres humanos tendemos a retomar algún hilo anterior, para seguir tejiendo los múltiples sentidos de nuestra vida y de nuestra historia. La resemantización en el fondo, es eso, el proceso de hacerle recomposiciones a la memoria, a las versiones de la existencia, aún sabiendo que probablemente no logremos modificarla mucho, porque intuimos que el significado de su eje de fondo, permanecerá el mismo. Y en ese punto se acaba la resemantización y empieza la interpretación. Entonces a otra cosa mariposa, vamos a compartir añoranzas.

Victorino Zecchetto sdb. Buenos Aires, Noviembre, 2010 